\title{
Acima do Equador: o que Sevcenko viu lá (ou História e Cultura como missão) ${ }^{1}$
}

\author{
Andrea Cristina Muraro² e Luiz Maria Veiga ${ }^{3}$
}


relacionadas à língua portuguesa. Falou-nos do seu trabalho na Universidade Harvard, das comunidades luso-falantes que há na Nova Inglaterra, dos papéis desiguais de Portugal e do Brasil na divulgação da língua e da cultura nos EUA e na Europa, de sua convivência com o professor Homi Bhabha e, ainda, do seu "engajamento lúdico" com o texto literário, na oportunidade em que se reedita sua tradução de Alice no país das maravilhas, o clássico de Lewis Carroll.

Nicolau Sevcenko, filho de imigrantes russos, nasceu em 1952, perto do final da primavera, entre o mar e o Orquidário, na cidade de São Vicente, na Baixada Santista e por causa disso torce pelo Santos Futebol Clube até hoje. Pequeno ainda, sua familia subiu a serra do Mar e se mudou para São Paulo. De coletor de metais usados para reciclagem, office boy, leitor voraz (ainda assim permanece) e excepcional jogador de handebol (foi heptacampeão nos Jogos Estudantis com o Colégio Américo de Moura e jogou ainda no Juventus, General Motors, São Caetano e Santo André) a professor e escritor, fez um pouco de tudo pelos quatro cantos da cidade.

Formou-se e doutorou-se em História Social na Universidade de São Paulo. Teve a honra de contar com Sérgio Buarque de Holanda em sua banca de doutorado, a última banca de que o ilustre historiador participou. Logo se tornou professor no Departamento de História da Faculdade de Filosofia, Letras e Ciências Humanas da universidade em que se formou e ali permaneceu até se aposentar. Trabalhou também na Pontifícia Universidade Católica de São Paulo, na Universidade Estadual de Campinas e, como professor-visitante, em universidades como a de Londres, no Reino Unido, as de Illinois e Georgetown, nos Estados Unidos, onde ainda atua, agora como professor titular na Universidade Harvard. Ligado às grandes questões do mundo contemporâneo, mantém uma colaboração ativa com jornais, revistas e publicações independentes.

Entre seus livros mais importantes estão $A$ revolta $d a$ vacina (1983, com reedição em 2010 pela Cosac Naify); Orfeu extático na metrópole: São Paulo nos frementes anos 20 (1992), seu trabalho de livre 
docência; A corrida para o século 21: no loop da montanha-russa (2001); Literatura como missão: tensões sociais e criação cultural na Primeira República (2003), sua tese de doutorado (de 1981, publicada originalmente pela Brasiliense em 1983, galardoada com o Prêmio Moinho Santista Juventude, na área de História do Brasil e com o Prêmio Literário São Paulo, como ensaio literário); além de organizar o terceiro volume da História da vida privada no Brasil: da belle époque à era do rádio (1998), todos pela Companhia das Letras. Atualmente trabalha num grande estudo sobre Hélio Oiticica e sua época.
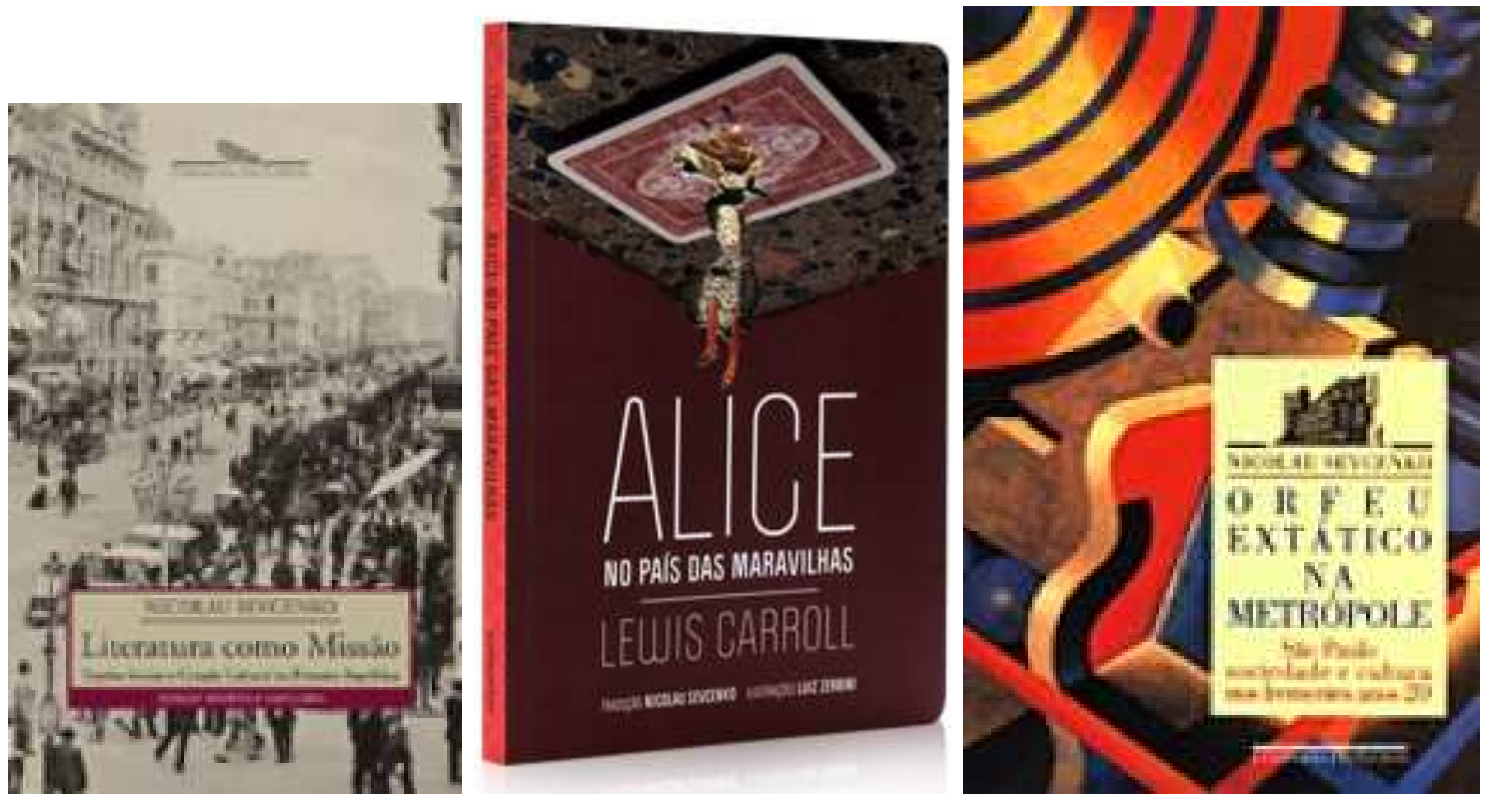

No campo mais específico do texto literário, Nicolau Sevcenko publicou o conto infantil "A lenda do fim dos gigantes e o surgimento dos homens", tocante história que desvenda a origem dos canhotos segundo uma velha tradição russa, no volume Vice-versa ao contrário (Companhia das Letrinhas, 1993). Também traduziu contos de fantasia de Oscar Wilde, no livro Histórias para aprender a sonhar (Companhia das Letrinhas, 1996). Mas confessa que sempre teve um encanto especial por Alice no país das maravilhas, obra que traduziu em meados da década de 1980 e que foi relançada pela Cosac Naify em 2009. Para a nova edição, Nicolau escreveu um posfácio e traduziu também os poemas que integram a narrativa, o que não havia feito da primeira vez. 
Revista Crioula - Fale-nos sobre como ocorreu a criação do David Rockefeller Center for Latin American Studies na Universidade Harvard e em que medida isto impulsionou os estudos sobre o Brasil.

Nicolau Sevcenko - Na cena das universidades americanas, há um papel tradicional dos departamentos de língua espanhola: ter desdobramentos na área de estudos latino-americanos, hispanoamericanos. Mas o Brasil nunca fez muito parte da cena acadêmica americana, apesar de ser metade da América Latina. Havia algumas poucas universidades que tinham bons acervos de fontes bibliográficas sobre o Brasil. Podemos lembrar, em Washington, a Universidade Católica da América, com o acervo originado pela doação da biblioteca de Oliveira Lima, reunida quando ele foi professor ali, e que, por isso, leva seu nome. Também há na Universidade do Texas ${ }^{4}$, em Austin, provavelmente o melhor acervo sobre o Brasil e a respeito do Brasil, organizado pelo prof. Richard Graham; e a Universidade de Yale, com um acervo muito mais sobre literatura e poesia, organizado pelo professor Andrew Jackson. Eram as três grandes referências. De qualquer forma, os estudos brasileiros estavam numa situação bastante minoritária. O tradicional e o consolidado era o estudo da cultura hispano-americana. Só que o interesse pelo Brasil, não faz muito, consolidou-se como um fenômeno nos EUA, e o David Rockefeller Center for Latin American Studies 5, organizado em Harvard, que nasceu há mais ou menos dez anos, foi criado com essa dupla dimensão: interessar-se não só pelos estudos hispano-americanos, também pelos luso-brasileiros. Neste sentido, assumiu um papel e tem uma condição de pioneirismo que, àquela altura, foi também incentivado pelo próprio governo dos EUA e por várias outras universidades. Isso veio, de certa forma, a reconfigurar o panorama acadêmico no que se refere aos estudos latino-americanos, colocando o Brasil como parte dessa cena. A minha própria contratação pela Universidade Harvard veio no sentido de reforçar a ala de estudos brasileiros, e particularmente, criar esta

${ }^{4}$ (http://www.utexas.edu/cola/insts/llilas/centers-andprograms/brazil/overview.php) 5(http://www.drclas.harvard.edu/) 
conexão entre os estudos brasileiros e latino-americanos. Assim, se a gente olha para o futuro, a tendência é haver uma inversão: acho que há um enorme investimento, enorme estímulo ao desenvolvimento dos estudos brasileiros e luso-brasileiros muito a partir da mudança da posição, da presença do Brasil, no contexto da economia internacional nas últimas décadas. A tendência atualmente é de um crescimento muito acentuado de matrículas dos alunos americanos em cursos relacionados a estudos luso-brasileiros, superando a procura por estudos hispano-americanos. É, portanto, um momento particularmente otimista e com o qual eu me identifico, sinto que posso ter um papel relevante e posso ajudar a definir este novo momento.

Revista Crioula - Hoje, os estudos luso-brasileiros abarcam principalmente o Brasil?

Nicolau Sevcenko - De longe o carro-chefe é o Brasil. Tradicionalmente havia um interesse mais forte em relação a Portugal. Mesmo nas áreas dos departamentos onde havia uma abertura maior para a língua portuguesa, era para o estudo de literatura portuguesa, havia uma ênfase muito maior do lado português do que do lado brasileiro, por conta da longa relação histórica dos EUA com Portugal. Como é sabido, Portugal deve a sua independência, em grande parte, ao patrocínio político e militar da Inglaterra, do Reino Unido, desde o tratado de Methuen [1703] e antes disso, desde a independência do Mestre de Avis [1385]. Depois da I e II Guerras Mundiais, esta situação se alterou. Portugal passou a ser fundamental na realocação das bases americanas ao redor do mundo; então as áreas remanescentes do império português espalhadas pelos continentes serviram para os EUA montarem uma rede de bases e, a partir disso, estabelecer uma forte relação com Portugal. O Departamento de Estado definiu o português como uma das línguas prioritárias para o ensino nos EUA. Recentemente, passou a haver uma destinação de verba pública anual para estímulo dos estudos dessa língua, o que é uma vantagem para as universidades que querem abrir departamento de língua portuguesa, 
porque recebem a verba suplementar muito generosa que sempre é imensamente bem-vinda. Mas, por essa relação histórica com Portugal, a ênfase sempre foi em língua portuguesa de Portugal, cultura portuguesa de Portugal e uma ênfase menor nas ex-colônias. O Brasil é que chegou há pouco neste contexto, ele não é só novo na sua relação com a América Latina, mas novo também na própria relação com Portugal, ao dividir com a antiga metrópole as atenções da lingua portuguesa. Hoje é muito natural, por conta da situação proeminente que o Brasil assume no bloco de países emergentes, que os estudantes tenham um interesse muito maior em aprender a língua portuguesa tal como ela é falada no Brasil e se familiarizar mais com a cultura, características econômicas, geográficas e sociais do Brasil do que com as de Portugal e das ex-colônias. De qualquer forma, a ênfase, o interesse maior é relacionado às ex-colônias, não a Portugal, na medida em que o perfil do aluno que procura estes cursos de língua e cultura luso-brasileiras tem uma inclinação para trabalho de motivação social junto a populações carentes, como medicina preventiva, apoio a comunidades excluídas, minorias e todo tipo de trabalho de ONG que tenha conotação ecológica. Por isso o Brasil e as ex-colônias têm muito mais poder de atração do que Portugal.

Revista Crioula - Angola, Cabo Verde ou Moçambique não têm visibilidade individual como literaturas de língua portuguesa entre os estudiosos da universidade?

Nicolau Sevcenko - A percepção ainda tende a criar uma espécie de associação coletiva e juntar as literaturas lusófonas de África como se fossem uma unidade, sem uma percepção nítida das variantes angolana, caboverdiana, moçambicana, e outras. Acredito que há uma tendência para quanto mais se tornarem objeto de interesse, mais nítida irá ficando a definição de cada um destes contextos. Mas, por enquanto, prefiro dizer que a percepção é de três blocos bastante nítidos: Portugal, Brasil e as ex-colônias, como se fossem homogêneas, o que obviamente não são. 
Revista Crioula - Portanto, há um interesse e os estudos começam a se desenvolver...

Nicolau Sevcenko - A Embaixada de Portugal, diante do fato de que os EUA sempre lhes deu um enorme apoio, inclusive apoio econômico e social, por conta dessa aliança politico-militar entre os EUA e Portugal, a Embaixada sempre foi ativa e sempre teve recursos vultuosos e os usou muito bem. Acho o trabalho deles bastante relevante. Por exemplo, investiu muito fortemente em produzir material didático, em difundir informações e centros de informação sobre a cultura portuguesa em universidades estratégicas, em áreas estratégicas, sobretudo naquelas que têm uma população luso-africana

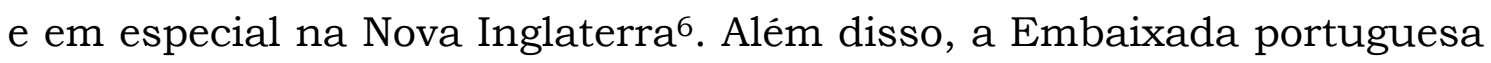
foi muito pró-ativa no sentido de criar uma rede de leitorado através do Instituto Camões: Portugal oferece e paga professores para oferecer cursos de português e cultura luso-africana em toda e qualquer instituição de ensino fundamental, médio ou universitário que solicite ou manifeste interesse. Isso dá a Portugal uma presença marcante e visivel no mundo educacional dos EUA de uma forma ampla e diversificada. Como atualmente há uma especial inclinação pelo universo africano que vem de dupla fonte: primeiro desse interesse de uma juventude ativista que está voltada para trabalho social, trabalho ecológico; e depois, dessa interface que há entre a abertura das instituições educacionais americanas para o mundo pós-racista em que se tenta adensar o significado histórico-cultural da minoria africana nos EUA. Aí a África, como um todo, acaba atraindo um grande interesse e toda escola tem uma série de atividades relacionadas ao estudo de culturas africanas. Então Portugal entra dando ênfase sobretudo nas culturas lusófonas no continente africano, e por isso esta parte tem crescido muito, a solicitação com relação ao mundo lusófono de África é cada vez maior. Portugal apóia, também, com esses recursos que vêm

6 Região localizada na ponta Nordeste dos EUA, inclui os estados de Connecticut, Maine, Massachusetts, New Hampshire, Rhode Island, Vermont. 
do Departamento de Estado e do Ministério da Educação, os programas relacionados aos países de África através de acordos internos desses países com Portugal e de Portugal com os EUA. No contexto da universidade onde trabalho é assim também, a Embaixada de Portugal promove atividades através do nosso departamento ou através do Centro David Rockefeller, e também através do Departamento de Estudos Afro-Americanos, em que há todo um grupo de disciplinas ligadas ao estudo de linguas africanas, ao estudo de cultura africana, religião africana, literatura, poesia, teatro e cinema africano. A Embaixada [de Portugal] tem uma relação muito intensa com este Departamento também, e é um outro campo pelo qual aparece a visão da tradição lusófona muito mais pelo perfil africano e de uma maneira também cada vez mais crescente. Por exemplo, recentemente tivemos, lá na Universidade Harvard, uma grande feira de livros caboverdianos pontuada com atividades relacionadas à leitura poética, montagem de teatro, apresentação de filmes, diferentes manifestações de música, canto, dança; enfim, uma semana de atividades relacionadas a Cabo Verde que teve uma grande repercussão não só no campus, mas na cidade e nas cidades vizinhas, onde há uma concentração populacional de portugueses e caboverdianos.

Revista Crioula - Fale-nos mais sobre essas comunidades de luso-falantes existentes na Nova Inglaterra, sobre sua origem, por exemplo.

Nicolau Sevcenko - É extraordinária a presença histórica de Portugal na região da Nova Inglaterra e do Canadá, por conta da faixa da pesca do bacalhau que se estende mais ou menos das ilhas do Atlântico (Açores, Madeira) e passando por Cabo Verde vai até a costa de Massachusetts onde está o Cabo do Bacalhau (Cape Cod) e até o Maine, no extremo Norte do EUA e, daí, para a Terra Nova, no Canadá. Desde o século XVII, há um fluxo de pescadores ingleses e canadenses que fazem esse circuito na direção das ilhas de Portugal, e um circuito oposto de pescadores portugueses que fazem esse trajeto na direção da 
costa ocidental do norte dos EUA. Estas duas comunidades se cruzam, a esta altura, quase que por três séculos e meio. O resultado disto é a fixação dessas comunidades portuguesas de várias gerações por inúmeras cidades que são quase completamente constituídas por portugueses e descendentes de portugueses das ilhas do Atlântico, e que mantêm uma espécie de cultura tripla: uma cultura que em parte tem a ver com a cultura nativa das regiões, a cultura portuguesa dominante a qual pertencem, e a cultura americana, o que dá um híbrido muito sugestivo, cheio de características peculiares e que combina elementos destas três heranças de maneira que permite que se faça hoje em dia a análise de uma literatura que é própria desse meio peculiar. Recentemente, houve, na Universidade de Brown, uma série de leituras poéticas, seminários e discussões de escritores especificamente relativos a este contexto americano-canadense de descendentes dessas comunidades de portugueses pescadores de bacalhau. E a pesca da baleia também, o museu da pesca da baleia fica justamente nesta área. Existe já, a esta altura, uma longa tradição de escritores e poetas que representam estas comunidades, com características marcantes de identidades históricas muito específicas e relativamente pouco conhecida em Portugal, pouco conhecido no Canadá e nos EUA, e muito menos conhecido ainda no Brasil.

Revista Crioula - O professor nos relatou como o governo português apóia os estudos lusos nos EUA. E o governo brasileiro, como se coloca na promoção e divulgação da língua portuguesa?

Nicolau Sevcenko - É uma outra coisa, uma história completamente diversa. O governo brasileiro sempre pode dizer que não conta com essa aliança político-militar e, portanto, não conta com o apoio financeiro, substancial. Mas o fato é que, do ponto de vista dos seus próprios recursos, o Brasil tem uma situação de incomparável superioridade com relação a Portugal. Nada justifica, portanto, a posição retraída e tão tímida na elaboração de sua política de divulgação da imagem e da presença da comunidade, da língua e da 
cultura luso-brasileira nos EUA, no Canadá e no exterior de uma forma geral. Existe um enorme sentimento, mesmo um ressentimento, nas pessoas ligadas aos estudos luso-brasileiros de que há uma descompensação, uma espécie de movimento de perneta neste caminhar da cultura luso-brasileira nos EUA. É um desequilíbrio entre uma situação meio nanica e uma posição de gigante, em que o lado português é o que se agiganta e o brasileiro mantém ainda esta posição nanica. Se há um esforço para superar isso, ele vem por outros caminhos, por exemplo, do próprio governo americano, do Departamento de Estado e do Ministério da Educação dos EUA, e de iniciativas isoladas de algumas universidades americanas e de alguns de seus centros de pesquisa, que não encontram correspondência no apoio colateral da Embaixada brasileira e de outros órgãos e institutos relacionados à educação e à difusão cultural e de pesquisa do Brasil no exterior. Como trabalhei um bom tempo no Reino Unido, posso dizer que a situação na Europa é semelhante à encontrada nos EUA, é uma espécie de omissão obstinada do sujeito diplomático brasileiro no sentido de promover essa melhor visibilidade e ampliação do interesse pela língua e pela cultura brasileira. É triste e lamentável dizer isso. Recentemente, uma colega do meu departamento participou na elaboração, em conjunto com outros colegas de universidades americanas, de um livro didático sobre ensino de lingua portuguesa, e que ensina a lingua de uma perspectiva em parte brasileira, em parte portuguesa e em parte africana. Cada capitulo tem três setores: o vocabulário específico, a forma específica de pronúncia e os contextos histórico-culturais específicos. Um livro que é realmente soberbo, pioneiro, e, neste sentido, constitui um modelo para o tipo de ensino de cultura que a gente gostaria de ver difundido cada vez mais, e que respeita esta tripartição com suas características, sem que nenhuma delas queira prevalecer - essa é a idéia básica. E nem preciso dizer que o livro contou com um enorme apoio da Embaixada portuguesa que, colateralmente, pode ajudar o lado africano. O lado brasileiro teve que se desenvolver sem qualquer tipo de apoio institucional, não podemos 
contar com o lado brasileiro. Espero que surja uma pressão, no exterior já existe, mas deveria existir aqui também, pelo menos para tentar criar uma mudança de atitude, ainda mais agora que o Brasil tem pretensões diplomáticas de assumir um novo papel e uma nova liderança, uma posição de destaque no Conselho de Segurança da ONU. Se existem estas ambições é evidente que será preciso investir para chegar nisso, e este investimento se faz no âmbito da difusão da língua e da cultura e dos conhecimentos a respeito do país.

Revista Crioula - De que maneira, na visão do professor, os estudantes da área de Estudos Comparados de Literaturas de Língua Portuguesa poderiam colaborar nessa difusão?

Nicolau Sevcenko - A tentativa de ampliação do interesse pelas culturas lusófonas no concerto das universidades, do ensino público nos EUA, passa através da divulgação de material educativo e cultural, material literário e poético, sobretudo veiculado por revistas especializadas. Há toda uma preocupação em tentar abrir espaço para estas publicações e dar a elas um novo fôlego, em especial naquilo que dê projeção às novas gerações, às expectativas de um mundo que está em transformação tão acelerada. Porque são estas novas gerações as mais capacitadas para captar a ascensão e o nervo sensível dessas expectativas no contexto da sociedade americana. No sentido mais amplo, acredito que este seja o caminho para que não só haja uma presença mais substancial do Brasil, mas, sobretudo, uma presença qualificada, para que as pessoas entendam as especificidades da cultura, da história do Brasil.

Revista Crioula - No departamento de Línguas Românicas, em Harvard, há uma revista eletrônica que possibilite esta divulgação a qual o professor se refere?

Nicolau Sevcenko - Sim, temos a Roman Sphere, Esfera Românica, dividida em quadrantes: um quarto da esfera é francófono, outro, italianófono, há um quadrante hispanófono e o lusófono. A ideia 
é que a revista seja uma oportunidade de cruzar a produção do departamento com outras feitas nos EUA, mas também, sobretudo, com produções significativas que estejam acontecendo nos diferentes recantos do mundo, no sentido de entender a língua numa dimensão cosmopolita. Por isso queríamos muito ter contato com gente que está fazendo trabalhos com este mesmo sentido - de tentar ampliar a rede de agregação e trocas, intercâmbios, de entender a língua portuguesa redimensionada por esta nova condição da globalização em que estamos vivendo e fazer com que a Esfera Românica seja uma espécie de encontro virtual dos entusiastas de uma língua portuguesa que não é mais nem de Portugal, nem do Brasil, nem de África, mas de todos nós, onde quer que estejamos, em qualquer canto do mundo.

Revista Crioula - Parece que existe uma resistência dos portugueses a considerar as coisas desta forma...

Nicolau Sevcenko - Há aí pelos menos dois lados. O histórico, é a matriz, portanto, claro, são mais zelosos da língua, eles têm uma cultura de preservação do patrimônio, do tesouro nacional, por isso são reticentes com aquilo que se possa considerar perda da característica originária, histórica da língua, com toda razão. Por outro lado, a beleza da língua portuguesa está na beleza da história de Portugal, que de um recanto tão diminuto do continente europeu se espraiou por todos os continentes e constituiu esta comunidade em escala planetária e com isso formou outras referências, outros repertórios, outros vocabulários que deram muito mais encanto, mais graça, muito mais elasticidade, muito mais comunicabilidade para a lingua portuguesa. Eu me lembro em particular de uma escritora moçambicana, em um encontro na Universidade de Brown, dizendo do entusiasmo que ela tinha pela língua portuguesa tal como ela é falada no Brasil, referindo-se ao sotaque, ao acento brasileiro, da impressão e da sensibilidade dela dizendo que: "a língua portuguesa falada pelos brasileiros é um português falado com açúcar". Achei particularmente encantadora essa maneira de referir-se ao nosso sotaque. E por estas e tantas, a língua só 
se torna mais cheia de nuances, de sutilezas, de encanto, como um diamante que vai sendo mais e mais lapidado. Quanto mais você lapida, mais cheio de facetas e mais brilhante fica - acho que esta é a graça. No entanto, o próprio Saramago tem uma expressão sobre a língua portuguesa em que ele diz que "num rio caudaloso, a parte do rio que permanece pura é a corrente que corre no centro, porque o que vai pelas margens conspurca-se de lama”. É uma visão bastante conservadora, do meu ponto de vista, porque na margem é que há o encontro com a terra, com outras naturezas, com outras criaturas, com outras plantas, com outras personagens, é ali que eu acho que o rio cumpre a sua história, é dali que ele vai tirando a terra e vai deslocando a geografia, recompondo a topografia do planeta e sendo um elemento ativo na reconfiguração da geografia física, acho que a parte manifestadora do rio é a margem. Os portugueses sempre voltam à metáfora do Saramago, enfim. Por outro lado, eles falam também por trás da precedência que lhes dá a escala de investimento que fazem em busca da difusão das culturas luso, brasileira e africana; por ter este papel de ser a componente que mais faz investimento, que possui a maior rede de difusão, de divulgação e presentificação da cultura nos EUA, e em escala maior na Europa também. Isto nos alerta para o quanto o papel do Brasil ainda é pequeno, retraído, não está de modo nenhum à altura do que o Brasil é, e, sobretudo, do que o Brasil pretende ser. Nesse sentido, os portugueses fazem muito bem em nos puxar as orelhas e nos desafiar a assumir uma posição muito mais próativa e de liderança, e em sermos protagonistas da nossa própria cultura.

Revista Crioula - Aqui no Brasil temos sempre presente na bibliografia da área os textos teóricos do professor Homi Bhabha. Como é a sua convivência com ele em Harvard?

Nicolau Sevcenko - O professor Homi Bhabha é uma figura notável e decisiva, porque ele é o homem da interface. Ele dirige um centro que tem um perfil semelhante ao Centro David Rockefeller, na 
medida em que ele não está ligado a Departamento nenhum, ele é uma espécie de ponto de encontro de vários departamentos. Chama-se Centro de Humanidades. Este centro articula atividades acadêmicas, convida professores de outras universidades de todas as partes do mundo para dar cursos e palestras, participar de debates, e, ainda, organiza atividades internas na universidade com as quais ele procura compor uma nova percepção, sobretudo, da comunidade asiática, a qual ele pertence, fazendo portanto o nexo dos EUA com as suas minorias, daí a relação dele com outro Departamento de minorias, o de Estudos Afro-americanos. Harvard, por incrivel que pareça, tem uma tradição própria de estudos latino-americanos e das comunidades indigenas, porque Harvard foi criada em território indígena e para a universidade ser instalada naquela região tiveram que negociar com os chefes locais e estes exigiram que a universidade sempre tivesse cursos de estudo de cultura indígena, e que houvesse um interesse e um engajamento na defesa dos direitos das populações indígenas. Em Harvard isto se tornou muito forte, daí os Departamentos de Estudos Afro-americanos e Latino-americanos. Com esta ênfase do professor Bhabha junto das comunidades orientais, sobretudo da Ásia Central em direção ao extremo asiático, com o Departamento de Estudos do Oriente Médio e com o Centro David Rockefeller, o que resulta é uma convergência em que toda espécie de mundo não-americano e nãoeuropeu têm um encontro, uma esquina onde todos eles possam trocar suas experiências e conversar com a pressão dominante de matriz europeia ou anglo-saxônica. Nesse sentido, Bhabha cumpre um papel decisivo na universidade, o de ser uma espécie de interlocutor dos diferentes mundos que se encontram na universidade contemporânea do mundo globalizado. A tradição americana é obviamente xenófoba, assim como a das universidades de linhagem europeia, centradas na cultura ocidental, e o que muda atualmente é esta sensibilidade de que esse mundo polarizado pela herança europeia e anglo-saxônica não funciona mais, não é mais hegemônico e nem há mais razão para assim ser. Agora, a universidade tem que se abrir curiosa ao mundo 
demograficamente muito mais expressivo, de culturas muito mais antigas, com valores e referências que não podem ser reduzidas ao quadro da cultura ocidental. Nesse sentido, a universidade tem um papel decisivo a cumprir na função de pioneira, para redimensionar o mundo globalizado com flexibilidade e arejamento, proporcionando trocas de experiências de tolerância e de compreensão mútua que nem a política, nem a diplomacia têm conseguido realizar satisfatoriamente. O papel pioneiro que o professor Homi Bhabha tem assumido é altamente inspirador para mim. Ele é uma das pessoas com quem tenho mais afinidade e com quem tenho o orgulho e a honra de ter colaborado de forma bastante forte nos últimos anos.

Revista Crioula - Para encerrar, um pouco da faceta literária: como foi o processo de tradução de Alice no país das maravilhas, de Lewis Carroll, recentemente reeditado pela Cosac Naify?

Nicolau Sevcenko - A tradução do Alice acabou sendo para mim uma espécie de projeto de vida. Primeiro, foi o encantamento com o texto ainda na infância, lido na versão do Monteiro Lobato, que é uma versão boa, mas bastante simplificada, bastante adaptada. E fui pulando para outras versões. Aprendi inglês, comecei a ler o texto em inglês e, à medida que o meu inglês melhorava, eu relia e relia. Nunca parei de ler este texto a vida toda. Quando surgiu o desafio de fazer a tradução, foi a pedido da Cristina Carletti, que trabalhava então como editora da Série Reencontro, na Scipione. Dediquei a essa tradução talvez todo um ano, já que eu tinha mais oportunidade de trabalhar nela em fins de semana e feriados. Mas esse sempre foi menos um trabalho e muito mais um engajamento lúdico, pois estamos diante de um texto em que cada palavra tem um peso peculiar que simultaneamente joga com a extrema simplicidade, porque os diálogos são postos no vernáculo de uma criança em idade pré-escolar e que obviamente pertence a uma elite educada, portanto tem um gabarito elevado, mas mesmo assim é o mais simples e claro possivel, e, no entanto, com esse repertório, ele consegue sugerir nuances relativas à 
pirâmide social, à caricaturização de personagens políticos, personagens acadêmicos, personagens da cena literária e poética inglesa. Então, quanto mais a gente estuda os personagens e as situações, mais a gente entende o contexto, porque nada, absolutamente nada é gratuito, nada deixa de ter uma referencialidade na história, na cultura, na língua, na tradição literária. Enfim, é um texto que demanda estudo em estado permanente, por causa da compreensão multidimensional das diferentes possibilidades de ressonância das palavras, das expressões e das circunstâncias montadas em que Alice vive. Nesse sentido, sei que é algo evasivo, inefável, que não vou conseguir dominar a vida inteira, e é nisto que persiste para sempre o mistério, a fantasia, o elemento de jogo, do lúdico e de encantamento com o texto da Alice. Para fazer esta nova versão, eu pude rever a tradução e atualizá-la, porque, depois de ter estado na cidade de Oxford e ter passeado pelo circuito onde viveu Carroll, a gente começa a entender diferentes conexões que nunca tinha percebido - por exemplo, o Grifo é um personagem de certos prédios públicos da cidade de Oxford, o Dodô, por exemplo, tem a ver com o Museu de História Natural da Universidade de Oxford, e assim por diante. É um aprendizado infinito e se eu pudesse fazer, daqui a alguns anos, uma outra versão, eu adoraria e tenho certeza de que ela seria diferente, e nem por isso iria considerá-la como a última.

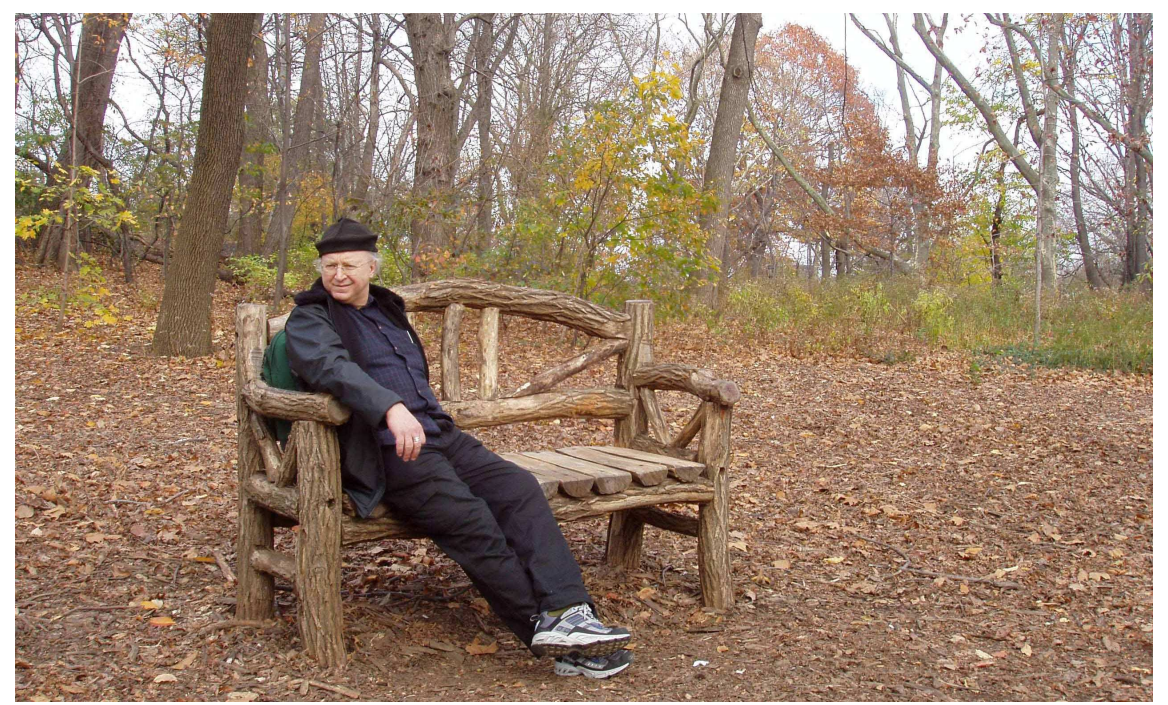

Foto: Cristina Carletti 